BULLETIN Bulletin hispanique

HISPANIQUE Université Michel de Montaigne Bordeaux

$120-2$ | 2018

Varia

Miguel Ángel García, Los autores como lectores.

Lógicas internas de la literatura española contemporánea

Madrid, Marcial Pons (Universidad y Lectura), 2017

Ginés Torres Salinas

(2) OpenEdition

Journals

Edición electrónica

URL: https://journals.openedition.org/bulletinhispanique/7473

DOI: 10.4000/bulletinhispanique.7473

ISSN: 1775-3821

Editor

Presses universitaires de Bordeaux

Edición impresa

Fecha de publicación: 10 diciembre 2018

Paginación: 706-711

ISBN: 979-10-300-0337-6

ISSN: 0007-4640

Referencia electrónica

Ginés Torres Salinas, «Miquel Ángel García, Los autores como lectores. Lógicas internas de la literatura española contemporánea», Bulletin hispanique [En línea], 120-2 | 2018, Publicado el 10 diciembre 2018, consultado el 08 enero 2022. URL: http://journals.openedition.org/bulletinhispanique/7473 ; DOI:

https://doi.org/10.4000/bulletinhispanique.7473

Este documento fue generado automáticamente el 8 enero 2022.

Tous droits réservés 


\title{
Miguel Ángel García, Los autores como lectores. Lógicas internas de la literatura española contemporánea
}

\author{
Madrid, Marcial Pons (Universidad y Lectura), 2017
}

Ginés Torres Salinas

\section{REFERENCIA}

Miguel Ángel García, Los autores como lectores. Lógicas internas de la literatura española contemporánea. Madrid, Marcial Pons (Universidad y Lectura), 2017, 305 págs. ISBN: 97-84-9123-425-8.

1 Casi dos décadas lleva ocupado Miguel Ángel García en desentrañar la lógica productiva de las principales líneas de fuerza de la poesía española contemporánea, desde que en 2001 publicara Vicente Aleixandre, la poesía y la historia (Granada, Comares) y El Veintisiete en vanguardia. Hacia una lectura histórica de las poéticas moderna y contemporánea (Valencia, Pre-Textos; I Premio Gerardo Diego de Investigación Literaria). Tal bagaje, que se extiende de las direcciones del modernismo al 27, de Juan Ramón Jiménez a la poesía social, cristaliza en la obra de la que en estas líneas nos ocupamos.

2 A través de un recorrido que comienza en Rubén Darío y finaliza en Antonio Carvajal, Miguel Ángel García se propone dar cuenta «de cómo unos autores leyeron puntualmente a otros autores y con ello se leyeron de paso a sí mismos» (p. 14). Sin embargo, el libro que aquí recensionamos está muy lejos de ser una mera recopilación biográfica de trayectorias lectoras o un ejercicio más de esa crítica hidráulica de la que hablaba Pedro Salinas. Antes al contrario, su intención es la de

mostrar hasta qué punto los autores son necesaria y previamente lectores, hasta qué punto leen de acuerdo con un inconsciente ideológico y estético, y lo hacen como una forma de construir su yo literario, para leerse a sí mismos, a partir de los autores leídos, para definirse mediante la tradición lejana o inmediata, incluso para situarse en el sistema o el campo literario del que forman parte, trazando afinidades 
y diferencias con respecto a los demás habitantes de esa tradición o de ese campo

(p. 15).

3 Tal intención supone que se puedan distinguir dos direcciones en este libro: por un lado, una reflexión sobre el ejercicio de la lectura y la significación e implicaciones que, para el autor, esta conlleva; de otra parte, el trazado de una red de lecturas efectuadas por los autores más importantes de la contemporaneidad literaria española, red que, gracias al análisis que de las mismas realiza García nos muestra un mapa fiel, riguroso y profundo de los presupuestos que han movido buena parte de la más importante literatura española desde Rubén Darío.

4 Por eso, el primer capítulo es la clave de bóveda sobre la que descansa el resto del volumen, en tanto que enuncia los presupuestos teóricos desde los que Miguel Ángel García lo construye. Ahondando en una propuesta teórica sobre la que lleva trabajando desde su primera obra, parte de que los autores aquí estudiados «son asimismo autores/actores situados en función social e ideológica, ya que así concibo la lectura, más que como acción espiritual, actualización del texto o constitución de sentido» (p. 23); cuestión sobre la que insiste poco después:

Más que por una lectura fenomenológia de la lectura, me inclino por hacer una lectura sociológica y sobre todo ideológica e histórica de la lectura [...] Hacer una lectura ideológica e histórica de la lectura, tal y como la entiendo, no equivale sin más a hacer una historia de la lectura, sino a subrayar la historicidad de toda la lectura (p. 29).

5 Merece la pena destacar al respecto cómo aplica Miguel Ángel García tal perspectiva a la siempre discutida cuestión de los clásicos en el capítulo III, «Cómo enseñar los clásicos. Fundamentos azorinianos». Aquí se explica cómo el acercamiento de Azorín a los clásicos, basado en el concepto de sensibilidad actual de los lectores con respecto a estos, se inserta en «un proyecto ideológico, el de la invención de España como nación liberal» (p. 67). La actitud del narrador alicantino sirve al autor para reflexionar con solidez, desde su perspectiva de profesor universitario, acerca del reto que supone enseñar a los clásicos en las aulas de educación superior, aunque bien pudiera servir para cualquier nivel. Sin dejar de reconocer, con Azorín, que «tan solo desde la conciencia del valor dinámico, móvil y cambiante de los valores literarios, tan solo postulando la naturaleza movediza del canon, los clásicos pueden seguir vivos, ser actuales y no una cosa muerta del pasado» (p. 59), García advierte con lucidez sobre el peligro de la desustanciación histórica de los textos a la que en ocasiones parece tender Azorín: «En las clases de historia de la literatura, los clásicos no se pueden enseñar viendo en ellos a nosotros mismos, porque de esta manera los leemos desde nuestro hoy, no desde su ayer, en su historia y en la lógica interna y productiva que los hace hablar» (p.64); cuestión que gravita sobre el análisis que en el quinto capítulo el autor hace de «La prosa del siglo XVI y el concepto de alma castellana en Azorín (1900-1924)».

6 A partir de aquí el libro puede dividirse en tres grandes bloques, en los que se nos mostrarán las lecturas concretas que los autores hacen unos de otros, siempre explicadas con admirable precisión histórico-literaria, historizadora, por seguir con la terminología usada por el atento lector que, a su vez, es Miguel Ángel García.

7 El primero de estos bloques se ocupa del inicio de la literatura contemporánea española, de finales del siglo XIX hasta la aparición del 27. El segundo capítulo del libro se centra en la lectura que un Rubén Darío cercano al regeneracionismo, y que podría calificarse «de escritor comprometido y aun de poeta social» (p.36), hace de Ángel Ganivet. Darío ve en el Ganivet encarnado en su héroe Pío Cid una conexión con don 
Quijote. El nicaragüense «se sumerge de lleno en el debate ideológico en torno a don Quijote -como símbolo decisivo a través del cual se afronta el problema de España-» (p.43), acercándose a partir del personaje de Cervantes a determinadas tesis regeneracionistas del granadino. Del mismo modo, explica García, el poema que Darío dedica a Ganivet ahonda en esta misma línea mediante el símbolo del cisne, de modo que «socializa y compromete ideológicamente su estética modernista, alejándola de esa supuesta evasión con la que demasiado a menudo se la ha caracterizado» (p.53). De Rubén Darío se ocupará también el capítulo IV, si bien esta vez será él quien sea leído. El análisis de los dos prólogos a la edición de 1890 de Azul..., obras respectivamente de Eduardo de la Barra y Juan Valera, muestra dos aspectos importantes para comprender la recepción de este libro tradicionalmente considerado fundador del modernismo: en primer lugar, que entre el prólogo del chileno y el del cordobés existe «una serie de reflejos, incluso de dependencias», hasta el punto de que el primero determina varios planteamientos del segundo (p.79), si bien cada uno lee a Darío según su propia perspectiva estética, siendo Valera quien condiciona las lecturas críticas posteriores; en segundo lugar, que el propio Darío, en aras de la canonización de su obra, de su intento de una mayor recepción, también lee el modo en que es leído, y así, «una vez recibida la crítica sancionadora de Valera, el prólogo de Eduardo de la Barra, escrito para la primera edición de 1888, va a ocupar un lugar secundario, hasta ser finalmente arrinconado» (p. 80).

8 Se cierra este primer bloque con un capítulo dedicado a la «Crítica alterna» que Juan Ramón Jiménez hizo de la poesía de Antonio Machado. A partir de reflexiones críticas del poeta de Moguer y su intercambio epistolar con el poeta sevillano, García demuestra cómo las diferentes visiones, las diferentes lecturas que el primero hace del segundo tienen su propia lógica. Así, Juan Ramón Jiménez insistiría en la marcada influencia de Rubén Darío a lo largo de la obra machadiana para hacer énfasis en cómo él mismo «se sacude a Darío antes que Machado, con lo cual la superación del modernismo [...] parte de él y solo de él» (p. 120). Del mismo modo, en su polémica con los jóvenes poetas de la llamada joven literatura, Jiménez leerá al primer Machado para colocarlo esta vez, junto a él mismo, como refundador de la poesía española merced a la «interiorización» que ambos aprendieron de Unamuno y que enlaza con la «corriente popular que, junto a la culta, singulariza nuestra poesía» (p.123). La actitud del Machado de Campos de Castilla supondrá dejar de lado «la contemplación de uno mismo» y la vida interior que interesan a Juan Ramón, con lo cual su juicio sobre este libro es su "completamente negativo» (p.139), en tanto que diverge de su proyecto estético. Así, explica García a raíz de un artículo juanramoniano de 1944, Jiménez sintetiza su lectura de Machado en los tres poetas que se reunirían en el sevillano: el discípulo de Darío, el de Bécquer y el poeta de lo castellano, siendo el segundo el mejor valorado por el moguereño, por cuanto es el que con más fuerza sintoniza con su poética (pp. 142-143).

El segundo bloque se centra en determinadas lecturas de y desde el 27. Así, el capítulo VII recoge el modo en que Rosa Chacel se ocupó del grupo de poetas que ha dado lugar a tal marbete. El análisis de Miguel Ángel García explica cómo la misma Chacel, al hilo del Ortega que patrocinó la incorporación a la modernidad de este grupo de jóvenes poetas, se acopla ella misma a dicha promoción (pp. 151-152). Chacel, explica el autor, «contribuye a la construcción historiográfica del 27 [y] reclama para sí el prestigio de la etiqueta», lamentando que el grupo de narradores vanguardistas no conociera la misma cohesión que el de los poetas, a la vez que proyecta sobre estos una visión «nostálgica y en cierto modo idílica», análoga a la del Dámaso Alonso de «Una generación poética 
(1920-1936)» (p. 157), artículo canónico en la historiografía del 27. La red de lecturas cruzadas prosigue en dos capítulos en que unos poetas se leen a otros. El VIII estudia la imagen que determinados textos de Pedro Salinas y Rafael Alberti ofrecen del «dramatismo lírico lorquiano» (p. 166), que no puede entenderse sin los esfuerzos por la estilización de lo popular que hace el 27. La lectura de Salinas se centrará en «lo popular andaluz y lo dramático también andaluz, o español en general» (p. 166), lo que lleva al granadino a ser «el gran poeta popular por haber creado el mito del pueblo andaluz». La misma idea la formula Rafael Alberti (p. 171), quien además se ocupa de leer los romances de Lorca para distinguirlos de los de Juan Ramón Jiménez y Machado, en tanto que aquel «inventa, por su parte, el romance dramático, lleno de escalofriado secreto, de sangre misteriosa» (p. 170). Otra posibilidad de lectura es la que la prosa crítica de Gerardo Diego hace de Vicente Aleixandre (capítulo X). Como bien se encarga de mostrar Miguel Ángel García, dicha lectura crítica tiene su asiento en el juicio estético del propio Diego, lo que explica que la poesía aleixandrina empezara a interesarle a partir del soneto a fray Luis de León que apareció en el número de homenaje al agustino que la revista Carmen le dedicó en 1928 (p. 194). A partir de ahí, la etapa de filiación surrealista de Aleixandre también merece la atención del santanderino, que la califica de romántica (pp. 198-199); atención que se sostendrá a lo largo de «medio siglo de lecturas -entre la amistad y el ejercicio crítico (pp. 201-204)bien desgranadas por García.

Especial atención se presta a Luis Cernuda, protagonista de hasta tres capítulos. El primero de ellos estudia «El andalucismo nórdico de Luis Cernuda». El Cernuda de los años treinta configura su poética a partir de una serie de lecturas que encaja a la perfección con ella. Su «rebeldía vital y poética» (p. 176), su «geografía lírica del deseo, o mejor, del ajuste entre realidad y deseo», supone la atención hacia poetas románticos ingleses y alemanes como Byron, Shelley, Keats, Goethe y Hölderlin (p.177). Con tal gesto, Cernuda intenta importar el auténtico Romanticismo a España, «traer la verdadera poesía moderna, instalarla entre nosotros» (p. 179). Tal Romanticismo nórdico, unido al inevitable interés por Bécquer, explican su particular «imagen de Andalucía, su andalucismo nórdico como ideología estética entre las diversas posibilidades del poetizar moderno que ofrece el 27» (p. 182).

Cernuda será objeto de atención de los autores del tercer gran bloque del libro, el dedicado a los poetas del grupo del 50. El autor parte de la correspondencia entre el poeta sevillano y Jaime Gil de Biedma para hablar, en el capítulo XII, no de «influencia» del primero en el segundo, sino de «confluencia» entre ambos (p. 227). El «Cernuda anglosajón» sirve a Gil de Biedma para «emanciparse de la tradición inmediata de la poesía social», para confirmarse en la poética que el catalán intenta conformar (pp. 230-231), y muestra de ello dan los textos críticos de Gil de Biedma y las cartas que ambos intercambian, bien estudiados por García. Francisco Brines encontrará también en Cernuda un referente mediante el cual podrá leerse a sí mismo, según se explica en el capítulo XIV. El poeta valenciano del 50 ve en el miembro del 27 «una alternativa a los defensores de la poesía como comunicación, incluso una alternativa al menoscabo que, como es usual decir, supuso la poesía social para la pura y simple poesía» (p. 267). A partir de tales presupuestos, García avanza paso a paso en la lectura que Brines hace de Cernuda en determinados textos teóricos, desde el ensayo de La caña gris en el número homenaje al sevillano hasta su discurso de ingreso en la Real Academia Española. 
12 Ángel González da pie a dos capítulos, uno como lector, otro como autor leído. El primero de ellos atiende a la lectura que del grupo del 27 hizo el poeta asturiano. García expone las líneas maestras de una recepción que se mueve entre la búsqueda de modelos «para el poeta social que se delineaba detrás del joven Ángel González» (p. 211) -lo que le lleva a acabar interesándose más por Machado que por el Juan Ramón Jiménez que leyó deslumbrado en su juventud (pp. 212-214)- y el reconocimiento de que, más allá de las reservas que González pudiera tener hacia la poesía pura, el 27 ocupa un lugar de privilegio en la poesía española del siglo XX (p. 218). El segundo texto es un brillante ejemplo de hasta qué punto las lecturas responden a una lógica ideológica. García toma la lectura que Alarcos Llorach hace de Ángel González o Blas de Otero, puramente lingüística, para explicar que la poesía queda «reducida a un discurso lingüístico esencial, formal, inmanente, al fin y al cabo destemporalizado, deshistorizado, universalizado», con lo que se diluye el compromiso que caracteriza a ambos poetas (p. 251).

El libro se cierra con un capítulo dedicado a la lectura que Antonio Carvajal hace de la imagen del jardín barroco de Soto de Rojas (pp. 287-292) y de «las batallas de amor que libran las fieras con sus presas en la selva aleixandrina» (p. 293), mostrando cómo son incorporadas ambas a una poética, la de Carvajal, que poco tiene de simple «Servidumbre de paso» intertextual y mucho de reflexión sobre cómo «no hay modernidad ni vanguardia -originalidad poética- sin tradición actualizada» (p. 289).

\section{AUTORES}

\section{GINÉS TORRES SALINAS}

Universidad de Granadaes 